\title{
Reforma agrária: de eleições a eleições
}

\author{
José JULIANO DE CARVALHO FILHO
}

$\mathrm{E}$ STE ARTigO CONSTITUI-SE em uma consolidação de outros trabalhos (1) sobre o mesmo tema, já publicados pelo autor, que visaram acompanhar a implementação da política fundiária do atual governo desde o período eleitoral de 1994 até o presente momento. Trata-se portanto, em boa parte, de material já publicado, cuja validade de nova publicação deve-se à proximidade de novo período eleitoral e também ao fato de que o atual presidente, embora não eleito com possibilidade de um segundo mandato, hoje dispõe desta oportunidade e é candidato.

Assim sendo, acredita-se válido apresentar aos leitores da revista ESTUDOS AVANCADOS dois relatos: o primeiro recordando o trato da reforma agrária no período eleitoral passado e o segundo analisando a sua implementação pelo governo de Fernando Henrique Cardoso, em paralelo à ação dos movimentos sociais. As conclusões desta segunda parte trazem algumas inferências para o próximo período eleitoral.

\section{A reforma agrária nas eleições de 1994}

A polarização ocorrida em torno do plano de estabilização, denúncias e inconfidências, empobreceu a campanha de 1994 e frustrou a discussão sobre importantes temas nacionais, entre os quais a reforma agrária.

O horário eleitoral que antecedeu o primeiro turno e os poucos debates ocorridos entre os candidatos à presidência da República davam a impressão de que existia consenso quanto à política fundiária a ser implantada pelo novo governo, qualquer que fosse. Praticamente todos os candidatos declararam-se a favor da reforma agrária e a incluíram nos programas de governo. Existia realmente este consenso ou tratava-se de algo apenas aparente?

Apesar das importantes transformações ocorridas no meio rural brasileiro nas três décadas anteriores às eleições, a questão da reforma da estrutura agrária brasileira não havia perdido atualidade. $\mathrm{O}$ processo de modernização conservadora da agricultura brasileira, que persiste até hoje, provocou expressivos resultados nos campos da produção e da agroindustrialização. Contudo, também implicou maior concentração e excludência. A estrutura fundiária permaneceu entre as mais concentradas do planeta - posição também mantida até o presente. Os indicadores relativos à distribuição de rendas e níveis de pobreza rural atingiram números ab- 
surdos. Um grande contingente populacional foi expulso do campo e hoje, tal como em 1994, sobrevive nos centros urbanos em condições insuportáveis de miséria. Os conflitos, a violência e a impunidade persistiram no campo, violentando a cidadania - situação que também caracteriza os dias atuais.

A reforma agrária, como uma das políticas públicas apropriadas para atacar esses problemas, deveria, portanto, ter sido objeto de amplo debate no período eleitoral. Não foi. Aparentemente todas as forças políticas concordavam em implementá-la. Todavia, a consulta aos programas de governo dos principais candidatos à presidência da República em 1994 permitia a constatação de algumas semelhanças e de importantes diferenças.

Quanto às semelhanças, além da posição favorável à reforma e do reconhecimento da relevância da questão social no campo, todos os programas consideravam a pequena produção familiar prioritária, declaravam a intenção de implementar políticas específicas de apoio a este segmento de agricultores e não discutiam claramente a questão dos recursos necessários para a implementação das ações previstas (2).

À primeira vista, as semelhanças apontadas acima poderiam indicar que os programas se igualavam em um alto nível de generalidades, dada a importância da reforma agrária como bandeira política em tempos de eleições presidenciais. Entretanto, a análise dos documentos indicava a existência de significativas diferenças conceituais.

Sob o título Reforma agrária moderna, o programa de Orestes Quércia não propunha, propriamente, uma reforma agrária. A proposta ali contida referia-se a projetos de assentamento e colonização, em áreas de fronteira agrícola em expansão, executados totalmente pela iniciativa privada e financiados pelo governo federal. A retórica utilizada foi a da interiorização do desenvolvimento e a estimativa de famílias a serem beneficiadas era de 400 mil para o período do mandato. O programa também acenava com a possibilidade do governo conceder incentivos fiscais para empresários dispostos a financiar projetos de colonização. A proposta de Quércia desconsiderava a problemática agrária das outras regiões do país, considerava erroneamente a situação da fronteira agrícola, ignorava a relação existente entre concentração fundiária e conflito agrário, não esclarecia a origem dos recursos e enfraquecia fortemente o importante papel do Estado na resolução da questão agrária.

O programa de Leonel Brizola colocava como princípio fundamental a democratização do acesso à terra, preconizava a eliminação da propriedade improdutiva e elegia a pequena propriedade familiar como modelo preferencial, sem prejuízo de outras formas de uso da terra. A implantação da reforma seria feita em duas etapas, a primeira visando ao alívio das tensões acumuladas pela expulsão das famílias rurais e a segunda objetivando transformar a estrutura agrária como um todo. Os instrumentos explicitados na proposta eram os seguintes: distribuição de terras; colonização; tributação de terras improdutivas; apoio aos assentamentos fundiários já existentes; e participação social. $\mathrm{O}$ texto do programa não era suficientemente claro, não indicava metas de assentados (embora falasse que o objetivo era criar milhões de novos proprietários) e não abordava a questão dos recursos. 
O candidato Enéas Ferreira Carneiro, no contexto geral de um discurso que revivia o ideário integralista de Plínio Salgado, também abordava o tema. A justificativa baseava-se no êxodo rural e nos problemas das populações camponesas e da produção agrícola. Os trabalhadores rurais sem acesso à terra eram divididos em dois tipos: produtores rurais de baixa renda, com baixa qualificação profissional; e produtores já possuindo um razoável nível técnico para a atividade de produção rural. Para este último grupo, o Estado evitaria grandes investimentos de capital e, além de desenvolver, intermediaria formas de arrendamento do tipo bolsa de terras. Quanto ao primeiro grupo, o programa propunha "uma reforma agrária de acomodação", efetuada pelo poder público, de cunho social e não visando necessariamente ao aumento da oferta agrícola. Neste caso, era prometido apoio às famílias dos produtores. A proposta não esclarecia o suficiente sobre o que vem a ser uma reforma de acomodação, não estabelecia metas quantitativas, não se referia especificamente à problemática do conflito rural e à questão agrária regional.

O documento, embora mencionasse as prioridades para a aplicação dos recursos públicos destinados ao problema agrário, também não esclarecia quanto às origens desses recursos. O que mais importa chamar a atenção quanto a esse então candidato é que a política agrária proposta, aparentemente apenas de acomodação, ou seja, paliativa e sem maiores pretensões de alterar a estrutura fundiária, fazia parte de um projeto nacional autoritário, caracterizado por uma doutrina central, ordem, disciplina, moralismo e ultranacionalismo. Em 1932, os integralistas também assim pregavam por uma nova ordem e começavam a tentativa de impô-la ao país.

Luís Inácio Lula da Silva apresentou o programa mais comprometido com a reforma agrária. Ela era considerada como uma política de caráter estrutural. O candidato propunha a implantação de um processo de reforma, em substituição às ações fundiárias esparsas que caracterizaram a política fundiária dos governos anteriores. A respeito, o texto do programa era muito claro quando afirmava: "Para nós, a reforma agrária designa o conjunto de transformações sociais e políticas resultantes do processo de reordenamento da atual estrutura fundiária do país, com a incorporação dos sem-terra e minifundistas à condição de trabalhadores autônomos". A segurança alimentar era considerada elemento estratégico do padrão de desenvolvimento. $\mathrm{O}$ conflito fundiário era tido como conseqüência da estrutura agrária vigente.

O programa propunha um plano de reforma para quinze anos e uma meta de 800 mil famílias assentadas para os quatro anos de governo. O programa também comprometia-se com a demarcação das terras indígenas. À crítica de irrealismo quanto à meta de assentamento de famílias, o programa respondia com o reconhecimento de que suas propostas dependiam da "criação e aperfeiçoamento dos instrumentos políticos e administrativos" e, como decorrência, do fortalecimento da capacidade do Estado para intervir na questão. Tratava-se da proposta de governo que mais esclarecia sobre os instrumentos que seriam utilizados. Considerava a desapropriação como o principal instrumento de distribuição de terras, estabelecendo limites superiores para propriedades não passíveis de desapropriação (500 hectares, nas regiões Sul, Sudeste e Nordeste; 1.000 hectares, no Centro-Oeste; e 1.500 hecta- 
res, na região Norte). A proposta envolvia cinco subprogramas: assentamentos; arrecadação de terras públicas; arrendamento e parceria; tributação de terras agrícolas; e reforma agrária com irrigação para o Nordeste. A visão de agricultura era bimodal, com fortalecimento da agricultura familiar e desenvolvimento da agricultura empresarial. A proposta também não esclarecia a questão dos recursos.

O programa do candidato Fernando Henrique Cardoso reconhecia a necessidade de profundas mudanças no campo e considerava a reforma agrária como medida importante para a resolução do problema da segurança alimentar, para o fortalecimento da agricultura familiar e para a redução dos conflitos agrários.

Embora os argumentos fossem parecidos com os de Lula, neste caso não se tratava de estabelecer um processo de reforma. O conceito de reforma agrária implícito no programa resumia-se a ações fundiárias mais agressivas quando comparadas com os governos passados, sem a menor pretensão de alteração estrutural.

As metas do programa para assentamento de famílias eram crescentes a cada ano, totalizando 280 mil famílias assentadas no final do mandato. Estas metas eram consideradas tímidas, embora realistas, dada a legislação vigente. O programa era omisso quanto à necessidade de alteração do aparato legal e origem dos recursos. $\mathrm{O}$ documento prometia apoio aos trabalhadores assentados e propunha ação articulada entre os três níveis de governo - federal, estadual e municipal - para a implementação de obras sociais e investimentos de infra-estrutura, com destaque para a região Nordeste.

A respeito de sua proposta, manifestava-se o candidato Fernando Henrique Cardoso: “(...) Os conflitos agrários existentes no Brasil são conseqüência de uma situação histórica que as políticas públicas não foram capazes de reverter. São necessárias, portanto, profundas mudanças no campo. O governo Fernando Henrique vai enfrentar essa questão, com vontade política e decisão, dentro dos princípios da lei e da ordem. Com a meta de aumento substancial dos assentamentos a cada ano, o objetivo é atingir a 100 mil famílias no último ano do seu governo. Essa é uma meta ao mesmo tempo modesta e audaciosa, já que os assentamentos nunca superaram a marca anual de 20 mil famílias". (...) “Adotar uma política realista e responsável, com o assentamento de 40 mil famílias no primeiro ano; 60 mil, no segundo ano; 80 mil, no terceiro ano e 100 mil no quarto ano" (3).

O discurso, contudo, trazia em seu bojo uma contradição fundamental. Ao mesmo tempo que reconhecia a necessidade de profundas mudanças no campo, o programa apresentado era impotente para tanto. $\mathrm{O}$ conceito de reforma agrária adotado, claramente compensatório, não apresentava condições para alterar o padrão de concentração fundiária que sempre existiu no meio rural brasileiro. Além disso, a coalizão eleitoral que apoiava o então candidato (e que hoje apóia seu governo), com participação expressiva de correntes tradicionalmente conservadoras e contra a reforma agrária, colocava em dúvida a viabilidade do próprio programa, apesar de seu caráter conservador. 
Em suma: Quércia reduzia o problema da reforma a projetos de colonização privada na fronteira; Brizola reconhecia-a em função dos conflitos mas não era claro quanto a sua importância estrutural; Enéas a definia como de acomodação no bojo de um projeto neofacista; Lula considerava-a claramente como política estrutural e propunha a implantação de um processo de reforma; e Fernando Henrique a tinha como política apenas compensatória, embora prometesse ação fundiária mais agressiva em relação aos governos passados. Ou seja, o consenso era apenas aparente.

\section{A política fundiária no governo de FHC}

Por ocasião dos acontecimentos em Eldorado de Carajás, este autor apresentou aos leitores de Informações Fipe (4) artigo que resumia a implementação da política fundiária brasileira desde o final dos governos militares até o período imediatamente posterior ao massacre de trabalhadores rurais sem-terra em Eldorado de Carajás. Naquela ocasião, quanto ao atual governo, foi apresentada a conclusão de que, essencialmente, nada havia mudado com relação ao passado; que as ações governamentais mais agressivas aconteceram como decorrência de agravamentos da questão política no campo - provocadas pelo acirramento do conflito fundiário e/ ou da agressividade dos movimentos sociais - dando a vã impressão de que tudo iria mudar e que, com o tempo, tudo voltaria ao que sempre foi, implicando na permanência da questão fundiária (5). Para expressar a conclusão da análise, o artigo recorreu ao escritor italiano Giuseppe Tomasi di Lampedusa em seu romance $O$ leopardo, citando o personagem Tancredi quando explica a seu tio, personificação da nobreza latifundiária italiana, as razões de sua adesão às forças republicanas: “ (...) Se queremos que tudo fique como está é preciso que tudo mude. Expliqueime bem?” (6). Vejamos se esta imagem ainda tem atualidade.

Uma vez empossado, o presidente Fernando Henrique Cardoso deu razão a seus críticos nomeando José Eduardo de Andrade Vieira para o Ministério da Agricultura e Brasílio de Araujo Neto para o Incra, pessoas cujos históricos, claramente, não as recomendavam para a implantação da reforma. Os movimentos sociais foram praticamente ignorados, em especial o Movimento dos Trabalhadores Rurais Sem Terra (MST). O desempenho dessas autoridades, somado à evidente má vontade da área econômica, comprovou que a meta de assentamentos para o primeiro ano de governo não seria alcançada. Nessa época, a tensão no campo mostrou-se crescente - multiplicando-se as ocupações de propriedades improdutivas pelos sem-terra - e ocorreu o primeiro grande massacre de trabalhadores em Corumbiara (RO).

Pressionado pelo agravamento da questão política decorrente do massacre e pela atuação dos movimentos sociais - o MST tornara-se o principal movimento de trabalhadores rurais da história da questão agrária brasileira -, o governo mudou de posição e nomeou Francisco Graziano Neto para o Incra, nome da confiança pessoal da presidência e familiarizado com a questão agrária. Graziano conseguiu apaziguar os ânimos, reduzir tensões e encaminhar a questão da reforma dentro e fora do governo. Esta situação durou pouco, culminando com a saída de Graziano devido ao episódio "grampo/Sivan”. Foi nessa época (final de 1995) que foram decretadas 
as prisões de Diolinda Alves de Souza, Márcio Barreto e José Rainha Júnior, todos ligados ao MST. Diolinda, acusada de "formação de quadrilha", foi presa e encaminhada ao pavilhão 2 da Penitenciária Feminina do Carandiru. Márcio também foi para a penitenciária. Rainha tornou-se um foragido da lei. Crescia a tensão no Pontal do Paranapanema. A questão social voltava a ser tratada como caso de polícia.

O imediato de Graziano assumiu o Incra interinamente e lá permaneceu por longos meses, terminando por ser efetivado no início de 1996. Nesse período, o governo anunciou que a meta de assentamentos para 1995 havia sido atingida e até superada, no que, com razão, foi contestado pelo MST, Contag e alguns analistas. A situação permaneceu dessa forma até a ocorrência do segundo grande massacre de trabalhadores sem-terra, em Eldorado de Carajás (PA). Os noticiários nacional e internacional deram grande destaque à chacina, mostrando que houve execuções. De início, o episódio foi considerado como "coisas do Brasil arcaico". Depois, frente a sua repercussão, o país acompanhou uma seqüência de fatos bastante conhecida: declarações indignadas por parte das autoridades - presidente e governador; promessas de "rigoroso inquérito" e de que os criminosos seriam punidos - "seja lá quem for!" (até hoje não o foram); e anúncio de medidas de repercussão por parte do governo - troca de autoridades e alterações administrativas.

Em resumo, o governo tomou uma série de atitudes, entre as quais destacaram-se a criação do novo Ministério Extraordinário de Política Fundiária - novamente retirando do Ministério da Agricultura a responsabilidade de executar a política fundiária - e a nomeação de Raul Jungmann para assumi-lo. O ministro Jungmann - oriundo do PPS - apresentava condições de diálogo com os movimentos sociais. Enquanto isso, a tensão no campo se agravava e entidades como a Confederação Nacional da Agricultura (CNA) recomendavam uso da força na defesa da posse da terra (7).

Assim o tempo foi passando. O governo anunciando algumas medidas (novo ITR, Rito Sumário), as ocupações aumentando; os jornais dando menos espaço para o massacre e para o andamento dos "rigorosos inquéritos"; os mesmos jornais e também televisões (principalmente) veiculando notícias procurando desqualificar os movimentos sociais, inclusive lançando dúvidas sobre as vítimas; o governo e seu ministro perdendo diálogo com os movimentos sociais (a relação com o MST foi praticamente rompida). Ou seja, apesar dos atritos com os movimentos sociais, a situação foi controlada e tudo voltou ao "normal". Até que começa a surgir uma nova questão política: o MST resolve fazer a marcha para Brasília.

De início, da mesma forma que estava fazendo com o Movimento, o governo menospreza o fato e ameaça o MST. Dois meses depois, dada a expressão política que a marcha assumiu, o mesmo governo recebe a liderança dos sem-terra. Afinal, os "primitivos", como diz o presidente, ou "os resquícios do Brasil arcaico", como querem outros, haviam chegado a Brasília - com capacidade de organização e mobilização popular. Contraditoriamente, os "resquícios" cresciam! A eles somavam-se outros "resquícios", estes modernos, conseqüentes da atual fase "moder- 
nizante" e "globalizante" da economia nacional. Eram os excluídos do processo de modernização, os "inempregáveis". A temperatura em Brasília subiu, teve até peru na mesa do ministro Kandir. A ave foi colocada pelos participantes de uma manifestação da Contag.

A respeito da mudança da atitude governamental sobre a marcha, relatou o jornalista Jânio de Freitas, em artigo publicado na Folha de S. Paulo: “(...) Há mês e meio, o ministro da Reforma Agrária, Raul Jungmann, negava qualquer possibilidade de simples conversa com alguém do Movimento dos Trabalhadores Sem Terra, ao qual negava o seu reconhecimento pessoal e, como ministro, o do governo. A presidência considerava que a marcha a Brasília não atingiria seu objetivo, porque Fernando Henrique não receberia a comissão dos sem-terra. O senador Antônio Carlos Magalhães avisava que não permitiria a manifestação dos sem-terra em frente ao Congresso. Todas essas atitudes estão substituídas pelo seu oposto. E ignorase o significado de tamanho recuo, no qual resta apenas recuar sem expor a humilhação, deixar fora da vista um embate que envolve mais do que as partes evidentes: alcança toda a ideologia em moda e suas representações e fins entre nós” (8).

Voltar atrás não é necessariamente um defeito, pode ser sabedoria ou uma virtude - reconhecimento de um erro. No entanto, o que se seguiu não foi nada virtuoso ou fruto de sabedoria. A marcha de Brasília foi um claro sinal de aumento das tensões sociais não só no campo, mas nas cidades.

Em clima de grande desconfiança, o governo, afinal, recebeu os sem-terra e propôs uma comissão. Em seguida, os jornais relataram uma seqüência de desentendimentos que resultaram na falta de acordo entre o governo e os trabalhadores. Má intenção de ambos os lados? Tentativas de colocar o Movimento em uma "arapuca"? Radicalismo do MST? Tentativa governamental de apenas amainar os movimentos sociais? Não se sabe. $\mathrm{O}$ fato é que as autoridades não tiveram capacidade (ou vontade?) política para conversar com os trabalhadores. As tentativas anteriores de isolar o MST devem ter pesado na balança.

Em seguida, para possibilitar negociações - supunha-se - Milton Seligman foi nomeado presidente do Incra e tomou posse no dia 2 de junho. Dez dias depois, o governo anunciou a MP $\mathrm{n}^{\circ} 1.577$ e o Decreto $\mathrm{n}^{\circ} 2.250$. Este, significando endurecimento com o movimento dos sem-terra, aquela (louvável), com medidas que facilitam a implementação da política fundiária. Ou seja, o confronto se agravou. $\mathrm{O}$ Movimento reagiu falando em outras formas de ocupação de terras. O pior dessa história é que o anúncio governamental se deu no mesmo dia em que ocorreu a condenação - no mínimo estranha - de José Rainha em Pedro Canário (ES). Coincidência? A respeito esclareceu o ministro à Folha de S. Paulo (9): “(...) Jungmann disse que as medidas estavam prontas havia meses mas não foram anunciadas quando da marcha do MST a Brasília, no dia 17 de abril, por decisão do presidente Fernando Henrique. 'Ele entendeu que não era o momento político correto, era melhor deixar que a sociedade visse qual a postura do MST com o governo', afirmou. (...) Não há um golpe nos movimentos sociais. Estamos abertos à conversa- 
ção. O que estamos fazendo é dar um basta na corrupção e nos conflitos agrários e acabar com o conluio do Incra com as invasões e superavaliações de terra, disse o ministro".

Desde então, o acompanhamento do noticiário evidencia duas linhas de atuação do governo. De um lado, mostra-se agressivo e operante na implementação da política fundiária anunciando diversas medidas importantes para a reforma agrária (projeto Lumiar, projeto Casulo, Cédula da Terra, aumento de recursos para o Pronaf, linha de crédito do BNDES para compra de terras e Recadastramento Nacional dos Imóveis Rurais), chegando a afirmar que está havendo uma "revolução cultural" (10) na reforma agrária brasileira. O presidente, em recente entrevista concedida à imprensa (aquela que anuncia a substituição do frango pela dentadura, como símbolo do Real), dedica grande parte de sua explanação inicial à política fundiária de seu governo. Diz que as metas de 1997/98 serão atingidas e afirma: “(...) Eu acho que é indiscutível que o governo, hoje, dispõe de capacidade de fazer assentamento. Muito menor do que aquilo que cada um de nós gostaria. Mas muito maior do que jamais se fez. (...) Nenhum governo se empenhou mais na questão da reforma agrária do que o atual governo (...)” (11). Esta última frase parece antecipar o slogan agrário que será utilizado na campanha eleitoral do próximo ano.

Por outro lado, a segunda linha de atuação governamental tem sido a crítica contínua aos movimentos sociais (principalmente ao MST), procurando desqualificálos e enfraquecê-los (já assistimos a iniciativas semelhantes no período da ditadura militar). O objetivo é mostrar que o governo teve e tem a iniciativa da reforma, quando se sabe, pela evidência dos fatos mostrada neste artigo (e nos anteriores), que este assunto voltou a ter relevância nacional devido à ação dos movimentos sociais. A respeito, é interessante destacar afirmativa extraída de artigo publicado na Gazeta Mercantil (12) referente à entrevista presidencial já citada: "Talvez o assunto mais longamente tratado na entrevista tenha sido o da reforma agrária, em uma tentativa de resgatar um pedaço da bandeira arrancada das mãos do governo pelo Movimento dos Sem Terra (MST)".

A idéia básica parece ser confundir a opinião pública provocando a sensação de que a reforma agrária não avança mais devido à má vontade, radicalismo e outras intenções dos movimentos sociais. A difusão dessa idéia, se conseguida, permitirá às forças políticas no poder controlar a situação e ter bandeira político-eleitoral (provavelmente com aumento das metas de assentamento), mantendo o caráter conservador da política fundiária, desprovido de qualquer pretensão real de alterar a estrutura agrária brasileira.

Enquanto isso, a tensão social no campo cresce, a União Democrática Ruralista-UDR (e outras organizações do gênero) se rearticula e a ocorrência de conflitos graves torna-se mais do que provável. Multiplicam-se as prisões de semterras no Paraná. O Superior Tribunal de Justiça (STJ) arquiva o inquérito que apurava a responsabilidade do governador do Pará, Almir Gabriel, no massacre de Eldorado de Carajás. O I Censo da Reforma Agrária não localiza 82.178 famílias 
(25\% do total) tidas como assentadas pelas estatísticas oficiais (13) e o ministro justifica dizendo que foi devido às chuvas (exagero, não acham?). Fazendeiros expulsam sem-terras de áreas ocupadas e cantam o hino nacional com ampla cobertura da imprensa. Surgem grupos de sem-terras independentes do MST (14). João Pedro Stédile alerta para o crescimento do conflito decorrente de "novos movimentos que, no desespero, apelam para a violência" (15). Governo e boa parte da imprensa confundem (para o público) os novos movimentos com o MST. O ministro Jungmann oferece o exército para ajudar o Estado do Paraná contra o Movimento (16). "Advogado da UDR orienta para atirar 'da cintura para baixo"” (17). Cai o nível de emprego nos centros urbanos e na agricultura (previsão tendo em vista a mecanização de culturas). Celso Furtado afirma que a exclusão social é o grande desafio (18). O governo anuncia que agora é a hora do social - o discurso de posse do presidente também assim o afirmava (19). E as forças políticas no poder, ou em torno dele, disputam a paternidade do plano Real.

(20).

Ou seja, como disse o presidente, "plus ça change, plus c'est la même chose"

Referências bibliográficas

1 "Reforma agrária: todos querem mudar a estrutura fundiária mas consenso é aparente". Folha de S. Paulo, Especial "Brasil 95 - Prova Final", 25/09/94, p. A-7.

"Eleições e política agrária". Informações Fipe n ${ }^{\circ}$ 169, out. 1994, p. 12-14.

“Política agrária: fatos e reflexões”. Informações Fipe n ${ }^{\circ}$ 184, jan. 1996, p. 11-13.

“Déjà pu na política agrária?”. Informações Fipe nº 189, jun. 1996.

"Política fundiária: oportunidades perdidas, revolução cultural e lampeduza". A ser publicado na revista São Paulo em Perspectiva, Fundação Seade, v. 12, nº 2.

“Política fundiária de FHC”. Informações Fipe n 204, set. 1997, p. 14-17.

2 Os candidatos Esperidião Amim e almirante Fortuna, cujos programas não são aqui analisados, também declararam-se favoráveis à reforma, no horário gratuito da televisão. O primeiro invocando a sua experiência em Santa Catarina e o segundo falando em "terras realmente disponíveis".

3 "Mudanças dependem de reforma no setor público" - "Reforma Agrária". O Estado de S. Paulo, 25/08/94, p. A-14.

4 “Déjà vu na política agrária?”. Informações Fipe nº 189, jun. 1996.

5 Este trecho do artigo reproduz, em parte, material contido nos seguintes artigos do autor: "Política fundiária: oportunidades perdidas, revolução cultural e lampeduza" (a ser publicado na revista São Paulo em Perspectiva, Fundação Seade, v. 12, nº 2 ) e "Política fundiária de FHC" (Informações Fipe n 204, set. 1997, p. 14-17.

6 Livro citado no texto, publicado pela Difusão Européia do Livro em 1963 (São Paulo, $3^{\text {a }}$ edição), p. 32 . 
7 Gazeta Mercantil, 13/05/96, p. A-5.

8 Jânio de Freitas. "Em pouco tempo". Folha de S. Paulo, 16/04/97, p. 1-5.

9 "Governo muda a lei e quer dar 'um basta' a invasões". Folha de S. Paulo, 13/06/97, p. 1-4.

10 Raul Jungmann. "O cadastro da terra". Folha de S. Paulo, 18/07/97, p. 1-3.

11 “Solução social não sairá da 'batina', diz FHC". Folha de S. Paulo, 02/09/1997, p. $1-6$.

12 “A entrevista do presidente". Gazeta Mercantil, 02/09/97, p. A-4.

13 Informação colhida na matéria "Sai o primeiro censo da reforma agrária". Gazeta Mercantil, 08/09/97, p. A-9.

14 A referência é para o "Movimento Sem Terra do Norte do Paraná" e para o "Movimento de Libertação dos Sem Terra (MLST)", que existe na região nordeste do país, ambos independentes do MST.

15 "Reforma Agrária - Líderes do MST afirmam que demora do governo estimula a ação de grupos autônomos no campo". Folha de S. Paulo, 13/09/1997, p. 1-9. A frase completa é a seguinte: "Não perdemos o controle da nossa base. O governo precisa abrir o olho, porque a política dele está criando um barril de pólvora, novos movimentos que, no desespero, apelam para a violência".

16 "Providência terrena". Painel. Folha de S. Paulo, 14/09/97, p. 1-4.

17 Manchete de matéria publicada no jornal Folba de S. Paulo (19/09/1997, p. 1-12) sobre a situação no Pontal do Paranapanema.

18 Entrevista de Celso Furtado para a jornalista Mônica Magnavita, publicada em $O$ Estado de S. Paulo (11/08/97, p. B-6) sob o título "Exclusão social é o grande desafio, diz Furtado".

19 Em seu discurso de posse, o atual presidente afirmou: "Falta a justiça social. É este o grande desafio do Brasil neste final do século. Será este o objetivo número um do meu governo".

20 Frase utilizada na entrevista à imprensa de $01 / 09 / 97$, publicada na Folha de S. Paulo $(02 / 09 / 97$, p. 1-7) na matéria "Leia a íntegra da entrevista coletiva concedida pelo presidente da República”. Na ocasião, o presidente não se referia à política fundiária.

Resumo - Aproveitando a proximidade das eleições para a presidência da República, o artigo apresenta dois relatos: o primeiro recordando o trato da reforma agrária no período eleitoral passado e o segundo analisando a implementação da política fundiária no governo Fernando Henrique Cardoso, em paralelo à atuação dos movimentos sociais. A conclusão é de que as iniciativas governamentais foram provocadas pelo agravamento do conflito no campo e pela ação dos movimentos sociais, em especial o MST, mantendo-se, contudo, o caráter conservador da política fundiária. Tendo em vistas as eleições 
de 1988, o governo tenta mostrar iniciativa na implantação da reforma agrária e procura desqualificar os movimentos sociais.

Abstract - This article, taking advantage of the presidential election nearness, presents two reports: the first one recollects the treatment given to the land property issue during the past presidential electing period, and the second examines the accomplishment of the land policy of the Fernando Henrique Cardoso's government, opposing to the social movements' struggle. The general conclusion is that the governmental initiatives have essentially been provoked by the aggravation of the land conflicts and by the attitudes of the social movements, in special the MST (peasants' movement), weighty nevertheless with the land property policy conservative attitude. Aspiring the next election contest, the government shows some initiatives towards the land property reform, trying nevertheless to disqualify the social movements' struggle.

José Juliano de Carvalho Filho é professor de Economia Agrícola do Departamento de Economia da FEA/USP e dos programas de pós-graduação em Ciência Ambiental e Nutrição Humana Aplicada da USP. 